\title{
Primary leiomyoma of the ureter: a case report
}

\author{
Shingo Morinaga', Shigeyuki Aoki', Motoi Tobiume², Genya Nishikawa², Hiroyuki Muramatsu², \\ Toyonori Tsuzuki ${ }^{3}$, Reiko Saiki ${ }^{4}$, Junko Hashimoto ${ }^{4}$, Kaori Mori ${ }^{4}$, Yoko Yamaguchi ${ }^{4}$, Akari Kobayashi ${ }^{4}$, \\ Tomoko Sawada ${ }^{5}$, Ruriko Futamachi ${ }^{5}$ and Yoshiaki Yamada ${ }^{1 *}$
}

\begin{abstract}
Background: Only 14 cases of leiomyoma with ureteral origin have been reported previously. Such primary leiomyomas often present as hydronephrosis, making the diagnosis difficult. Radical nephroureterectomy is often performed because of the possible diagnosis of a malignant tumor. We report the 15th case of primary leiomyoma with a ureteral origin.
\end{abstract}

Case presentation: A 51-year-old Japanese man presented with a chief complaint of asymptomatic gross hematuria with a history of hypertension. Enhanced computed tomography showed a tumor at the upper part of the right ureter that appeared to be the cause of hydronephrosis and contracted kidney; no retroperitoneal lymphadenopathy and distal metastasis were observed. A well-defined 20-mm (diameter) defect was identified at the upper of the right ureter on retrograde pyelogram with no bladder cancer on cystoscopy. Urine cytology and right divided renal urine cytology findings were negative. Laparoscopic nephroureterectomy was performed, and the extracted tumor measured $20 \times 13 \mathrm{~mm}$. Histopathological examination revealed primary leiomyoma with no recurrence 16 months after the operation.

Conclusions: Preoperative examination with the latest available ureteroscopic technology can help preserve renal function in the case of benign tumors by enabling preoperative ureteroscopic biopsy or intraoperative rapid resection. Moreover, nephroureterectomy is recommended in the case of preoperative suspicion of ureteral malignant tumors.

Keywords: Primary leiomyoma of the ureter, Ureteral neoplasm, Ureteral leiomyoma

\section{Background}

Primary leiomyoma rarely develops in the urogenital organs. There have been even fewer reports of leiomyoma of ureteral origin. Ureteral leiomyomas often cause hydronephrosis, which make their detection and diagnosis. Therefore, radical nephroureterectomy is often performed owing to the possibility of malignancy.

*Correspondence: yamada-yoshiaki@kani.jcho.go.jp

1 Department of Urology, Japan Community Health Care Organization, Kani Tono Hospital, 1221-5 Dota, Kani, Gifu 509-0206, Japan

Full list of author information is available at the end of the article
Our patient also underwent laparoscopic nephroureterectomy for right ureteral cancer. The present report describes this case and includes a review of the relevant reports in literature. To the best of our knowledge, this is the 15th case of primary leiomyoma with a ureteral origin.

\section{Case presentation}

A 51-year-old Japanese man visited our department with a chief complaint of asymptomatic gross hematuria in November 2019 with a history of hypertension. Family history was unremarkable. original author(s) and the source, provide a link to the Creative Commons licence, and indicate if changes were made. The images or other third party material in this article are included in the article's Creative Commons licence, unless indicated otherwise in a credit line to the material. If material is not included in the article's Creative Commons licence and your intended use is not permitted by statutory regulation or exceeds the permitted use, you will need to obtain permission directly from the copyright holder. To view a copy of this licence, visit http://creativecommons.org/licenses/by/4.0/. The Creative Commons Public Domain Dedication waiver (http://creativeco mmons.org/publicdomain/zero/1.0/) applies to the data made available in this article, unless otherwise stated in a credit line to the data. 
At the first visit, height and weight of the patient were $179 \mathrm{~cm}$ and $93 \mathrm{~kg}$, respectively. Blood pressure was $128 / 78 \mathrm{mmHg}$, pulse was regular with 62 beats/minute. and body temperature was $36.4{ }^{\circ} \mathrm{C}$. The patient had no history of smoking or drinking.

There were no specific abnormalities or neurological findings at the initial physical examination. Blood biochemistry revealed no abnormal findings, and urinalysis revealed microscopic hematuria with red blood cells (RBC) 20-29/high-power field (hpf) and white blood cells (WBC) $1-4 / \mathrm{hpf}$.

Abdominal computed tomography (CT) revealed hydronephrosis and contracted right kidney, in addition to fatty liver. Enhanced CT showed a tumor in the upper part of the right ureter, with a density similar to the ureteral wall, which appeared to be the cause of hydronephrosis and no retroperitoneal lymphadenopathy (Fig. 1A, B). Distal metastasis was not observed. A well-defined 20-mm (diameter) defect was identified at the upper right ureter on retrograde pyelogram (RP) (Fig. 1C), with no bladder cancer on cystoscopy; therefore, the findings of urinary cytology and right divided renal urine cytology were classified as class I.

Based on the above findings, the patient was diagnosed with contracted kidney with right ureteral cancer (cT2, N0, M0) and right hydronephrosis, and the condition was close to that of a nonfunctional kidney; laparoscopic nephroureterectomy was performed.
The extracted specimen was a nonpapillary, broadbased, solid tumor measuring $20 \times 13 \mathrm{~mm}$ with a yellowish-white cut surface (Fig. 2A).

Histopathological findings showed an increase in spindle cells with an interlacing fascicular pattern, mild nuclear atypia, and no mitotic figures (Fig. 2B). Because immunostaining showed $\alpha$-smooth muscle actin (SMA) (+) (Fig. 2C), h-caldesmon (+) (Fig. 2D), S-100 (-), C-KIT (-), cytokeratin (-), Melan-A (-), and human melanin black (HMB) 45 (-) (Fig. 2E), it was diagnosed as a primary leiomyoma from the ureteral muscularis.

Neither recurrence nor occurrence of leiomyoma was found in the contralateral urinary tract and other genitourinary organs 16 months after surgery.

\section{Discussion}

Nonepithelial benign ureteral tumors of mesodermal origin are rare, and primary ureteral leiomyomas are even rarer [1]. According to our research, only 14 cases have been reported since the first report published by Leighton et al. in 1955 [2-15], making the present patient the 15th (Table 1). Apart from one patient being an infant, most of the patients were aged between 30 and 60 years (average age 41 years), including the present case, aged 51 years. The lesions were located in the right ureter in seven, left in seven, and bilaterally in one. Nine patients were men, and six were women. The site of the lesion was upper, middle, and lower parts in eight, two, and five, respectively. There were no significant differences in the sex, lesion location, and site of development.

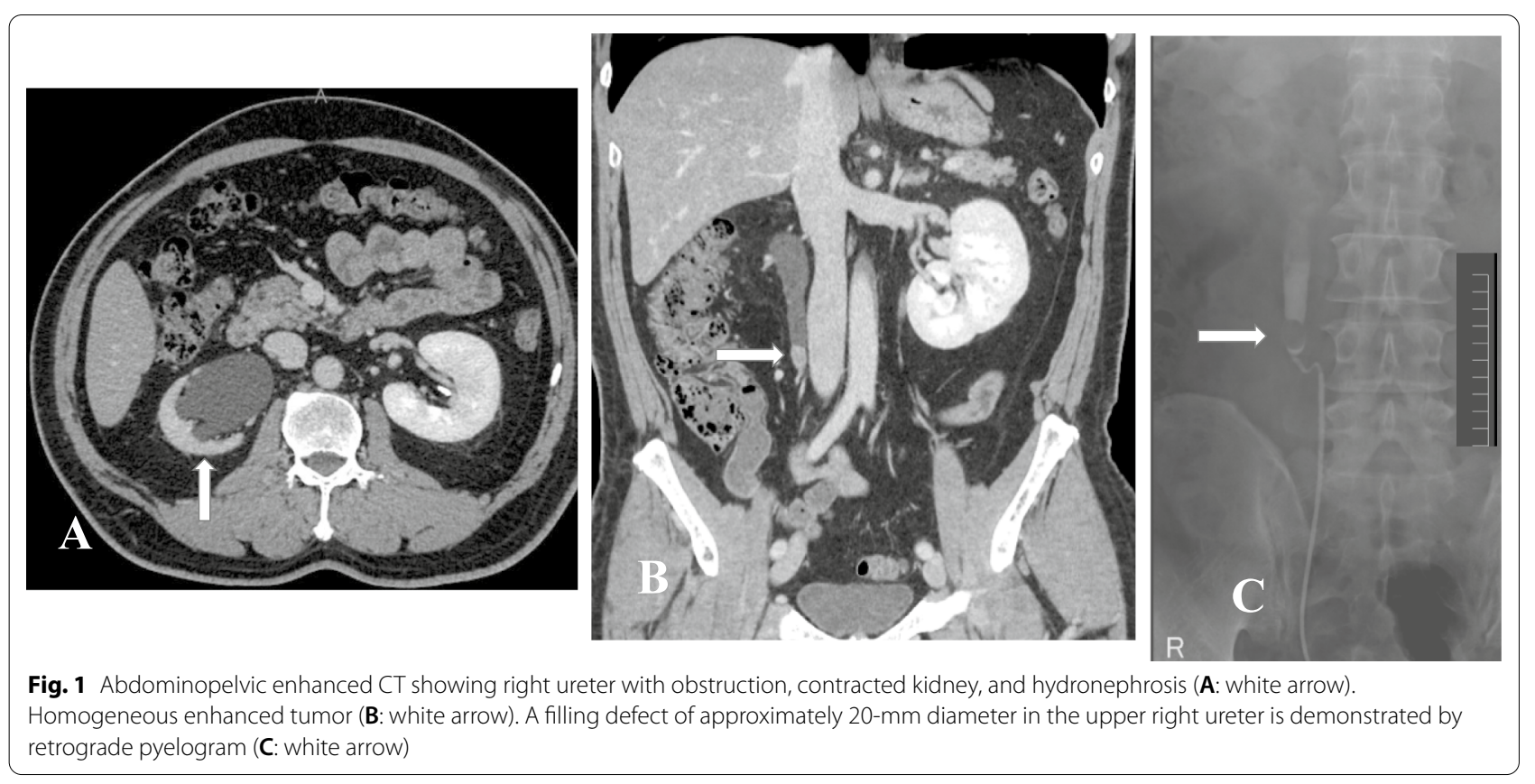




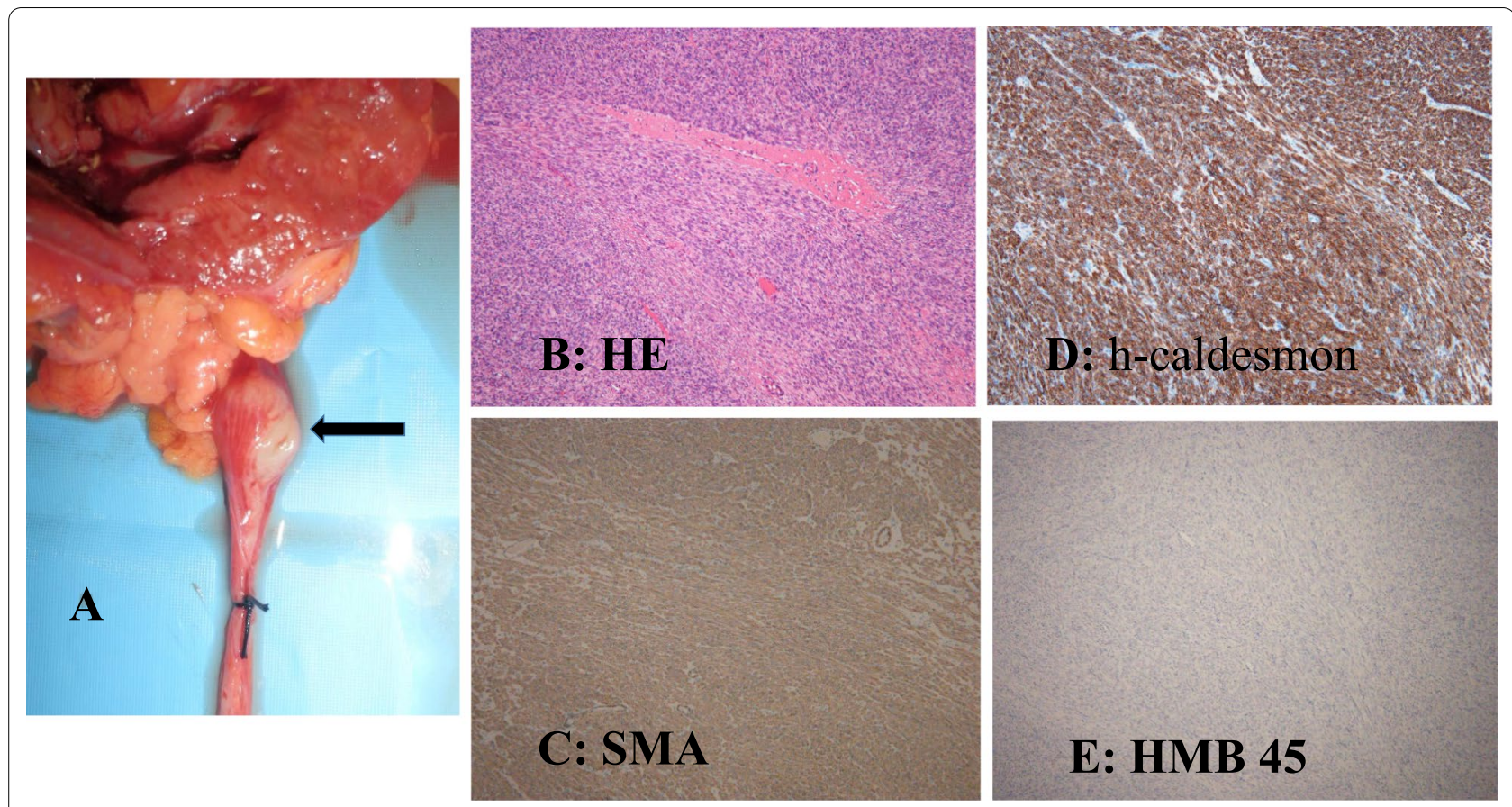

Fig. 2 Nephroureterectomy specimen showing a solid tumor measuring $20 \times 13 \mathrm{~mm}$ with a yellowish->white cut surface (A: black arrow). The pathological findings showed interlacing fascicular growth of spindle cells (B) [hematoxylin and eosin (HE) $\times 100]$. Immunohistological findings showing positive staining for a-smooth muscle actin (SMA) (C) and h-caldesmon (D), and negative staining for human melanin black (HMB) 45 (E) $(\times 100)$

Table 1 Reports of ureteral leiomyoma after 1955

\begin{tabular}{|c|c|c|c|c|c|c|}
\hline Reference & Age & Sex & Side & Size $(\mathrm{mm})$ & Location & Treatment \\
\hline Leighton [2] & 45 & $\mathrm{~F}$ & Rt & Quite small & Upper & Nephroureterectomy \\
\hline Kao et al. [3] & 34 & $\mathrm{~F}$ & $\mathrm{Lt}$ & 50 & Upper & Nephroureterectomy \\
\hline Mondschin et al. [4] & 4 & M & Rt & $20 \times 15 \times 10$ & Upper & Nephroureterectomy \\
\hline Sekar et al. [5] & 35 & $\mathrm{~F}$ & Rt & Micronodules & Lower & Ureterectomy \\
\hline Zaitoon [6] & 48 & M & $\mathrm{Lt}$ & $25 \times 20 \times 15$ & Lower & Partial ureterectomy \\
\hline Cussenot et al. [7] & 48 & M & Rt & 2 & Lower & Ureteroscopic biopsy \\
\hline Igarashi et al. [8] & 60 & M & $\mathrm{Lt}$ & $10 \times 5 \times 5$ & Middle & Nephroureterectomy \\
\hline Yashi et al. [9] & 40 & $\mathrm{~F}$ & Rt & 7 & Upper & Partial ureterectomy \\
\hline Ikota et al. [10] & 40 & M & $\mathrm{Lt}$ & $15 \times 13 \times 12.2$ & Upper & Nephroureterectomy \\
\hline Naruse et al. [11] & 38 & M & Rt & $35 \times 13$ & Lower & Partial ureterectomy \\
\hline Nouralizadeh et al. [12] & 24 & M & $\mathrm{Lt}$ & $120 \times 110 \times 75$ & Middle & Partial ureterectomy \\
\hline Wang HS et al. [13] & 24 & M & Billateral & Unknown & UPJ & Partial ureterectomy \\
\hline Zehri et al. [14] & 32 & $\mathrm{~F}$ & $\mathrm{Lt}$ & $112 \times 70 \times 15$ & Upper/middle & Nephroureterectomy \\
\hline Englund et al. [15] & 57 & F & $\mathrm{Lt}$ & 36 & Lower & Tumor resection \\
\hline Present case & 51 & M & Rt & $20 \times 10$ & Upper & Nephroureterectomy \\
\hline
\end{tabular}

UPJ: Ureteropelvic junction

The tumor sizes of the 12 cases described ranged from 2 to $120 \mathrm{~mm}$ (average size $37.5 \mathrm{~mm}$ ), and were also various.

Although the increasing use of laparoscopic morcellation techniques for hysterectomy and management of fibroids has been associated with reports of intraperitoneal seeding and growth of intraperitoneal daughter fibroids [16], and Kho et al. described the increased use of laparoscopic treatments for fibroids, with either myomectomy or morcellation of the fibroids, or laparoscopic hysterectomy with morcellation, 
secondary leiomyoma of the ureter, which grows from the extraureteral wall, may become a more common disease in the coming years [17].

Although inflammation, chronic stimulation, occlusion, and trauma are suspected, the mechanism of primary ureteral leiomyoma development remains unclear. Two patients had a history of ureterolithiasis, but not the present patient. Ikota et al. [10] reported a diffuse leiomyoma of the ureter as a complication of multiple endocrine neoplasia (MEN) type 1 . In MEN type 1 , the complication of multiple leiomyomas is recognized in a variety of organs, including the esophagus, stomach, lungs, uterus, and skin, but this case was the only one to develop leiomyoma in the ureter. It has been suggested that the MEN type 1-associated gene may have a causal relationship with multiple leiomyoma.

There are no clinical symptoms peculiar to this disease, and many patients are discovered by chance during a detailed examination of other diseases. However, our patient presented with a chief complaint of asymptomatic gross hematuria. The diagnosis is made by diagnostic imaging such as excretory urography, RP or CT, and urinary cytology, as for other ureteral tumors, but there are no characteristic findings.

Differential diagnosis as a benign disease includes perivascular epithelioid cell tumor (PEComa), ureteral polyps, and papilloma, but no characteristic diagnostic imaging method has been established.

Surgical treatment was performed in 14 of the 15 patients. Partial ureterectomy preserving the kidney was performed in only seven patients. Of patients who underwent partial ureterectomy, five were diagnosed by intraoperative rapid section and only two by ureteroscopic biopsy. In the other seven patients, nephroureterectomy was performed without differential diagnosis of benign or malignant tumors before surgery. As our patient was suspected of having cancer in the right ureter with contracted kidney and right hydronephrosis, and the condition was close to that of a nonfunctional kidney, laparoscopic nephroureterectomy was performed.

It has become possible to diagnose benign tumors by preoperative examination as a result of advancements in ureteroscopic technology in recent years. Therefore, if renal function is good and benign tumors are suspected in young people, ureteroscopic biopsy or rapid intraoperative pathology should be performed to make an active histopathological diagnosis, and it is important to pay careful consideration to the preservation of renal function.

\section{Conclusions}

Primary leiomyoma of the genitourinary tract is rare and difficult to diagnose before surgery. Preoperative examination can help preserve renal function in the case of benign tumors by efficient diagnosis and appropriate treatment. Nephroureterectomy in the case of suspicion of ureteral malignant tumor is a logical option.

\section{Abbreviations}

CT: Computed tomography; RP: Retrograde pyelogram; SMA: Smooth muscle actin; MEN: Multiple endocrine neoplasia; PEComa: Perivascular epithelioid cell tumor; HMB 45: Human melanin black 45.

\section{Acknowledgements}

The authors wish to thank the patient and his family for allowing them to publish this work.

\section{Authors' contributions}

SM drafted the manuscript. TT performed pathological diagnosis. SA, MT, HM, and GN treated the patient. RS, JH, KM, YY, and AK cared for the patient. TS and RF coordinated the patient between hospital and clinic cooperation. YY supervised the writing of this report. All authors read and approved the final manuscript.

\section{Funding}

None.

\section{Availability of data and materials}

Not applicable.

\section{Declarations}

Ethics approval and consent to participate

In our institution, institutional review board approval is not required for a case report.

\section{Consent for publication}

Written informed consent was obtained from the patient for publication of this case report and any accompanying images. A copy of the written consent is available for review by the Editor-in-Chief of this journal.

\section{Competing interests}

The authors declare that they have no competing interests.

\section{Author details}

${ }^{1}$ Department of Urology, Japan Community Health Care Organization, Kani Tono Hospital, 1221-5 Dota, Kani, Gifu 509-0206, Japan. ${ }^{2}$ Department of Urology, Japan Organization of Occupational Health and Safety, Asahi Rosai Hospital, 61 Hirakocho, Owariasahi, Aichi 488-8585, Japan. ${ }^{3}$ Department of Pathological Diagnostics, Aichi Medical University School of Medicine, 1-1 Karimata, Nagakute, Aichi 480-1195, Japan. ${ }^{4}$ Division of Nursing, Japan Community Health Care Organization, Kani Tono Hospital, 1221-5 Dota, Kani, Gifu 509-0206, Japan. ${ }^{5}$ Division of Hospital and Clinic Coordination, Japan Community Health Care Organization, Kani Tono Hospital, 1221-5 Dota, Kani, Gifu 509-0206, Japan.

Received: 6 April 2021 Accepted: 15 June 2021

Published online: 03 August 2021

References

1. Abeshouse BS. Primary benign and malignant tumors of the ureter; a review of the literature and report of one benign and twelve malignant tumors. Am J Surg. 1956;91:237-71.

2. Leighton KM. Leiomyoma of the ureter. Br J Urol. 1955;27:256-7. 
3. Kao VC, Graff PW, Rappaport H. Leiomyoma of the ureter. A histologically problematic rare tumor confirmed by immunohistochemical studies. Cancer. 1969;24:535-42.

4. Mondschein LJ, Sutton AP, Rothfeld SH. Leiomyoma of the ureter in a child. The first reported case. J Urol. 1976;116:516-8.

5. Sekar N, Nagrani B, Yadav RV. Ureterocele with leiomyoma of ureter. Br J Urol. 1980;52:400.

6. Zaitoon MM. Leiomyoma of ureter. Urology. 1986;28:50-1.

7. Cussenot O, Teillac P, Billebaund T, Roge P, Cortesse A, Leduc A. Leiomyomas of the urinary tract. Ann Urol (Paris). 1989;23:305-8.

8. Igarashi H, Onodera S, Nakada J, Nishida A, Shirai T, Machida T. A case of leiomyoma of the ureter. Jpn J Clin Urol. 1994;48:328-30.

9. Yashi M, Hashimoto S, Muraishi O, Tozuka K, Tokue A. Leiomyoma of the ureter. Urol Int. 2000;64:40-2.

10. Ikota H, Tanimoto A, Komatsu H, Ozawa Y, Matsushita H. Ureteral leiomyoma causing hydronephrosis in Type 1 multiple endocrine neoplasia. Pathol Int. 2004;54:457-9.

11. Naruse K, Yamada Y, Aoki S, Taki T, Honda N, Iwafuchi H. A case of primary leiomyoma of the ureter. Int J Urol. 2007;14:248-50

12. Nouralizadeh A, Tabibi A, Mahmoudnejad N, Taheri M, Torbati PM. Partial ureterectomy for a huge primary leiomyoma of the ureter. J Pak Med Assoc. 2010;60:62-4.
13. Wang HS, Huang $\mathrm{CH}$, Chen MT, Wu WJ. Bilateral ureteral leiomyoma with bilateral ureteropelvic junction obstruction. Kaohsiung J Med Sci. 2010:26:150-3.

14. Zehri AA, Ali A, lqbal F, Jessca M. Primary leiomyoma-a rare tumour of ureter. J Pak Med Assoc. 2013;63:268-70

15. Englund M, McCredie S, Robson S. Leiomyoma of the ureter. ANZ J Surg. 2017;87:E92-3.

16. Ostrzenski A. Uterine leiomyoma particle growing in an abdominal-wall incision after laparoscopic retrieval. Obstet Gynecol. 1997:89:853-4.

17. Kho KA, Anderson TL, Nezhat CH. Intracorporeal electromechanical tissue morcellation: a critical review and recommendations for clinical practice. Obstet Gynecol. 2014;124:787-93.

\section{Publisher's Note}

Springer Nature remains neutral with regard to jurisdictional claims in published maps and institutional affiliations.
Ready to submit your research? Choose BMC and benefit from:

- fast, convenient online submission

- thorough peer review by experienced researchers in your field

- rapid publication on acceptance

- support for research data, including large and complex data types

- gold Open Access which fosters wider collaboration and increased citations

- maximum visibility for your research: over $100 \mathrm{M}$ website views per year

At BMC, research is always in progress.

Learn more biomedcentral.com/submissions 